\title{
Article
}

\section{The Financial Burden of Opioid-Related Abuse among Surgical and Non-Surgical Patients in Florida: A Longitudinal Study}

\author{
Jing Xu ${ }^{1}\left(\mathbb{D}\right.$, Nazik M. A. Zakari ${ }^{2} \mathbb{(}$, , Hanadi Y. Hamadi ${ }^{1, *}$, Sinyoung Park ${ }^{1}$, Donald Rob Haley ${ }^{1}$ and Mei Zhao ${ }^{1 \oplus}$ \\ 1 Department of Health Administration, Brooks College of Health, University of North Florida, \\ Jacksonville, FL 32224, USA; jasper.xu@unf.edu (J.X.); sinyoung.park@unf.edu (S.P.); \\ rhaley@unf.edu (D.R.H.); mzhao@unf.edu (M.Z.) \\ 2 College of Applied Sciences, Al Maarefa University, Riyadh 11597, Saudi Arabia; nzakari@mcst.edu.sa \\ * Correspondence: h.hamadi@unf.edu
}

check for updates

Citation: Xu, J.; Zakari, N.M.A.; Hamadi, H.Y.; Park, S.; Haley, D.R.; Zhao, M. The Financial Burden of Opioid-Related Abuse among Surgical and Non-Surgical Patients in Florida: A Longitudinal Study. Int. J. Environ. Res. Public Health 2021, 18, 9127. https://doi.org/10.3390/ ijerph18179127

Academic Editor: Aziz Rahman

Received: 16 July 2021

Accepted: 27 August 2021

Published: 30 August 2021

Publisher's Note: MDPI stays neutral with regard to jurisdictional claims in published maps and institutional affiliations.

Copyright: (c) 2021 by the authors. Licensee MDPI, Basel, Switzerland. This article is an open access article distributed under the terms and conditions of the Creative Commons Attribution (CC BY) license (https:// creativecommons.org/licenses/by/ $4.0 /)$.

\begin{abstract}
Florida is one of the eight states labeled as a high-burden opioid abuse state and is an epicenter for opioid use and misuse. The aim of our study was to measure multi-year total room charges and costs billed for opioid abuse-related events and to compare the costs of inpatient opioid abusers and non-opioid abusers for Florida hospitals from 2011 to 2017. We constructed a retrospective case-control longitudinal study design on inpatient administrative discharge data across 173 hospitals. Opioid abuse was defined using both ICD-9-CM and ICD-10-CM systems. We found a statistically significant association between opioid abuse diagnosis and total room charge. On average, opioid abuse status increased the room charges by $8.1 \%$. We also noticed year-to-year variations in opioid abuse had a remarkable influence on hospital finances. We showed that since 2015 , the differences significantly increased from $4-5 \%$ to $13-14 \%$ for both room charges and cost, which indicates the financial burden due to opioid abuse becoming more frequent. These findings are important to policymakers and hospital administrators because they provide crucial insight into Florida's opioid crisis and its economic burden on hospitals.
\end{abstract}

Keywords: opioids; opioid abuse; hospital; surgical; non-surgical; economic burden; United States

\section{Introduction}

Opioids are defined by the National Institute on Drug Abuse as a class of drugs that include the illegal drug heroin, synthetic opioids such as fentanyl, and pain relievers [1]. Opioid abuse has risen to epidemic levels in the United States and was declared a public health emergency in 2017 [2,3]. Around 2 million people aged 12 or older suffered an opioid use disorder in 2018 [1], and 47,600 deaths were attributed to opioid-related abuse in 2017, highlighting increases in deaths among non-Hispanic blacks and Hispanics [4]. Fortunately, opioid-involved death rates decreased by 2.0\% from 2017 to 2018, which may be explained by efforts to reduce high-dose opioid prescribing practices [4]. Since the mid-2000s, Florida has been called an epicenter of the opioid epidemic, with opioid-related deaths increasing by $80 \%$ from 2003 to 2009 [5]. For this reason, the Prescription Drug Monitoring Program (PDMP) was initiated in September 2011. Although PDMP implementation helped opioidrelated deaths decrease overall [6], the overdose death rate in Florida remained high at 15.8 per 100,000 in 2018 , with the national average being 14.6 per 100,000 [7].

Opioid-related abuse has caused a marked increase in economic burdens, such as increased healthcare costs, workplace costs including reduced wages, lower employment, loss of worker productivity, and criminal justice costs [8,9]. The total economic burden was estimated to be $\$ 1021$ billion at the national level and $\$ 68,444$ million in Florida alone in $2017[10,11]$. The healthcare costs of opioid abuse in particular, calculated based on payer reimbursements to providers, have risen over time, mainly driven by the treatment of substance abuse, rehabilitation, inpatient, and emergency department (ED) costs [12,13]. 
The number of hospital charges and ED visits doubled from 2014 to 2017 due to opioid abuse, dependence, or overdoses [14]. This increasing trend in opioid abuse and misuse may be due to a more acute care population of patients in hospitals resulting in an increased prescribing of opioids [15]. Opioid abusers had higher healthcare utilization compared to the average population, including inpatient, outpatient, ED visits, and rehabilitation facility utilization $[13,16,17]$. Prior studies utilized medical and pharmacy claims data from 1998 to 2002 of self-insured employer health plans and found that opioid abusers are 12 times, four times, and 63 times more likely to have an inpatient stay, an ED visit, or an outpatient visit, respectively, compared with non-abusers matched by age, gender, employment status, and census region [17]. Opioid abusers are also more likely to have higher 30-day readmission rates and longer in a drug rehabilitation facility longer relative to matched non-abusers $[13,18]$. Similarly, prescription drug utilization was higher for opioid abusers than controls [19]. These phenomena could be explained by opioid abusers having higher rates of baseline comorbidities, such as pain and mental disorders, and higher chances of having other substance abuse disorders than non-abusers.

Higher healthcare utilization has increased healthcare costs for opioid abusers directly [20]. Numerous prior studies have examined healthcare costs associated with opioid abuse. Healthcare cost estimates vary across studies depending on study population characteristics, such as being insured, being on Medicare or Medicaid, specific healthcare events such as overdoses, and methods for measuring costs. However, those studies commonly indicate that healthcare costs tend to be higher for opioid abusers compared to non-abusers [12,13,16,17,21-23].

As such, for a population that is privately insured, annual healthcare costs were $\$ 18,000$ higher for opioid abusers patients than non-abusers [17]. A separate study analyzing administrative claims from self-insured recipients found that the average annual healthcare cost of opioid abusers per patient was $\$ 20,343$, compared to $\$ 9716$ for controls [13]. A second analysis was conducted using a different administrative claims dataset with the same matching approach and had similar results [16]. A recent study also confirmed that opioid abusers had $\$ 14,810$ higher healthcare costs annually [12]. A national study that analyzed Medicaid-covered opioid abusers reported that opioid abusers accumulated approximately triple the healthcare costs of non-abusers [21]. Some studies analyzed hospital charges related to opioid abuse. Higher hospital charges were driven by an increase in the utilization of ED services and inpatient admissions for opioid abusers, which are especially high among Medicare or Medicaid-covered opioid abusers [24,25].

Much of the previous literature analyzed healthcare utilization and direct costs associated with opioid abuse, using commercially available insurance claims data, managed care plan claims data, and Medicare/Medicaid claims data. However, there is limited literature investigating the financial burden of hospital services for opioid abusers from a hospital perspective. Therefore, the purpose of this study was to examine the difference in financial cost, measured by total room charge and cost, between opioid and non-opioid abusers across all Florida inpatient hospital discharges from 2011 to 2017.

\section{Conceptual Framework}

Based on the literature and the factors that impact opioid use hospital treatment expenditure, we developed the following framework guided by the framework developed in 2019 by Leslie, et al. [26]. The framework focuses on the path of patients with pain conditions. These patients may begin to use prescribed opioid medication and may become addicted which can result in an opioid-abuse diagnosis. Treatment is typically sought out and initiated in the ED and leads to further healthcare services including but not limited to inpatient services (e.g., hospitalizations and residential rehabilitation services). Our framework describes the financial path that opioid abuse hospital treatment and how it may drive up hospital expenditure. To evaluate the difference in financial cost, measured by total room charge and cost, between opioid and non-opioid abusers, we first followed patients with opioid use disorder treatment and their entry point to the hospital 
system. This entry point is often initiated in the emergency department and leads to further healthcare service use. In this model, we used hospital total room charge and cost from administrative claims data. We believe that patients with opioid use disorder may require additional treatment for secondary conditions presented due to the opioid disorder. We only include hospital expenditures and do not include insurance reimbursement payments or patient out-of-pocket payments.

\section{Methods}

\subsection{Data Sources}

The Florida Inpatient Discharge (FID) dataset was utilized in this study to examine the financial impact associated with opioid use. Inpatient discharges for all Florida hospitals from 2011 to 2017 were obtained from the Agency for Health Care Administration's Center for Health Information and Transparency. The data consisted of over 13 million de-identified medical claims records for each inpatient encounter and recorded patients' medical, financial, and demographic information. The data recoded up to 30 diagnosis and procedural codes per encounter, making it a comprehensive dataset. The data also provided a hospital identifier known as the Medicare Provider Number. Using this identifier, the dataset was linked to the 2011-2017 American Hospital Association (AHA) annual survey to populate hospital-related information. The AHA collects information on all U.S. hospitals' organizational structure, financing, workforce, and care delivery.

\subsection{Variables and Measures}

\subsubsection{Outcome Variable}

Our primary outcome variable was a single inpatient hospital stay-related charge for all encounters between 2011 and 2017.

\subsubsection{Case and Control Groups}

In this study, each encounter was assigned to be in either a case (opioid abuse) or control (non-opioid abuse) group based on whether it had a diagnosis of opioid abuse. Our inclusion criteria for both control and treatment groups were patients admitted to a hospital for treatment between 2011 and 2017. We included in the control group patients without an opioid diagnosis. In the treatment group we included patients with at least 1 opioid abuse diagnosis. We excluded any patients with missing data. Opioid abuse diagnosis was determined using both primary or secondary ICD-9-CM and ICD-10-CM codes presented in Table 1. The codes were identified and extracted based on prior research that used ICD-9-CM and ICD-10-CM codes and the Healthcare Cost and Utilization Project (HCUP) $[27,28]$.

\subsection{Matching Procedure}

Due to the low incidence rate of the opioid abuse case in the overall sample $(<2 \%)$ and a high absolute number of opioid abuse cases across the study period, [29] a propensity score method (PSM) was applied to create homogeneous matched samples for the final analysis [30]. The PSMATCH procedure from SAS 9.4 (Statistical Analysis System, Cary, North Carolina, United States) was applied to complete the propensity score matching.

For each opioid abuse case, the matching chose the non-abuse case that minimizes the difference between the logits of the propensity scores. The "greedy nearest neighbor" matching algorithm was used with a caliper width of 0.25 . The matching procedure was independently applied by yearly quarters (28 quarters). All opioid encounters were matched with non-abuse encounters on 1 to 1 ratio by patient age, gender (male or female), race (White, African American/Black, Latino/Hispanic, Asian, or other), primary surgical procedure (yes or no), length of stay, and Elixhauser comorbidity index, among which patient gender was required match exactly. Surgical procedures were defined using Healthcare Cost and Utilization Project (HCUP) Surgery Flags software for ICD-9-CM and ICD-10-CM [27,28]. Furthermore, we used a two-digit surgical procedure code prefixes 
which are listed in Table 2. We also matched specific hospital characteristics that have been previously identified as having an important impact on hospital charges across the entire study period. These hospital characteristics were hospital location (rural or urban), size (small < 100, medium < 400, and large 400+ inpatient beds), ownership (for-profit, not-for-profit, or government), and teaching affiliation (major, minor, or non-teaching).

Table 1. ICD-9-CM And ICD-10-CM Opioid-Abuse Diagnosis Codes.

\begin{tabular}{ccc}
\hline ICD-9-CM Code & ICD-10-CM Code & Description of Opioid Abuse \\
\hline 305.50 & & Unspecified \\
305.51 & Continuous \\
305.52 & Episodic \\
& F11.10 & Uncomplicated \\
& F11.120 & With intoxication, uncomplicated \\
F11.121 & With intoxication delirium \\
& F11.129 & With intoxication with perceptual disturbance \\
& F11.14 & With intoxication, unspecified \\
& F11.150 & With an opioid-induced mood disorder \\
& W11.151 & With opioid-induced psychotic disorder with \\
& F11.159 & With opioid-induced psychotic disorder with \\
& F11.181 & hallucinations \\
& F11.182 & With opioid-induced psychotic disorder, unspecified \\
& W11.188 & With opioid-induced sexual dysfunction \\
& F11.19 & With other opioid-induced disorder \\
& & With unspecified opioid-induced disorder \\
\hline
\end{tabular}

Table 2. Listing of HCUP Prefix Two-Digit Surgical Procedures.

\begin{tabular}{|c|c|}
\hline Principal Procedure & Description of Surgical Operation \\
\hline \multicolumn{2}{|l|}{ ICD-9-CM } \\
\hline 01-05 & Nervous System \\
\hline $06-07$ & Endocrine System \\
\hline $08-16$ & Eye \\
\hline $18-20$ & Ear \\
\hline $21-29$ & Nose, Mouth, And Pharynx \\
\hline $30-34$ & Respiratory System \\
\hline $35-39$ & Cardiovascular System \\
\hline $40-41$ & Hemic And Lymphatic System \\
\hline $42-54$ & Digestive System \\
\hline $55-59$ & Urinary System \\
\hline $60-64$ & Male Genital Organs \\
\hline $65-71$ & Female Genital Organs \\
\hline 74 & Cesarean Section and Removal of Fetus \\
\hline $76-84$ & Musculoskeletal System \\
\hline $85-86$ & Integumentary System \\
\hline \multicolumn{2}{|l|}{ ICD-10-CM } \\
\hline 00 & Central Nervous System and Cranial Nerves \\
\hline 01 & Peripheral Nervous System \\
\hline 02 & Heart and Great Vessels \\
\hline 03 & Upper Arteries \\
\hline 04 & Lower Arteries \\
\hline 05 & Upper Veins \\
\hline 06 & Lower Veins \\
\hline 07 & Lymphatic and Hemic Systems \\
\hline 08 & Eye \\
\hline 09 & Ear, Nose, Sinus \\
\hline
\end{tabular}


Table 2. Cont.

\begin{tabular}{cc}
\hline Principal Procedure & Description of Surgical Operation \\
\hline OB & Respiratory System \\
OC & Mouth and Throat \\
OD & Gastrointestinal System \\
OF & Hepatobiliary System and Pancreas \\
OG & Endocrine System \\
OH & Skin and Breast \\
OJ & Subcutaneous Tissue and Fascia \\
$0 \mathrm{~K}$ & Muscles \\
OL & Tendons \\
OM & Bursae and Ligaments \\
ON & Head and Facial Bones \\
OP & Upper Bones \\
OQ & Lower Bones \\
OR & Upper Joints \\
OS & Lower Joints \\
$0 \mathrm{~T}$ & Urinary System \\
$0 \mathrm{U}$ & Female Reproductive System \\
$0 \mathrm{~V}$ & Male Reproductive System \\
OW & Anatomical Regions, General \\
$0 \mathrm{X}$ & Anatomical Regions, Upper Extremities \\
$0 \mathrm{Y}$ & Anatomical Regions, Lower Extremities \\
\hline
\end{tabular}

The room charge and estimated cost (room charge multiplied by the cost-to-charge ratio) were analyzed separately by generalized linear models [31]. with lognormal distribution and identity link function using SAS 9.4 [32]. The experiment factor-opioid abuse status-was included in the model as a fixed covariate [33]. All the matching variables mentioned in the previous section were also included as covariates. Besides the main effect of opioid abuse on both financial metrics, we also examined the impacts by year and surgical status.

\section{Results}

The distribution of room charges and hospital cost are provided in Table 3 by year. The distribution shows that for room charges the largest difference between our control and the treatment group was in 2015, while the smallest difference was in 2014. For hospital costs the largest difference was reported in 2015, with a $20.58 \%$ difference between treatment and control groups, while the smallest difference was in 2012. The final sample sizes and matching statistics (total absolute differences) are provided in Table 4. The analysis of room charges and cost per encounter was provided in Table 5. It shows, on average, that opioid abuse status increases room charges by $8.1 \%$ with a $95 \%$ confidence interval $(7.1 \%$, $9.1 \%)$, and increases the room cost by $8.6 \%$ with a $95 \%$ confidence interval $(7.6 \%, 9.6 \%)$ per encounter.

We also examined how the differences varied year to year, as well as whether the differences varied between surgical and non-surgical patients. Therefore, we conducted a longitudinal analysis with stratified comparisons. It was also noticed that the year-to-year variations of the influence of opioid abuse on hospital finances are remarkable. Compared with the control groups, the increases in in-room charges and cost are consistently higher from 2011 to 2017. The differences are about $5-8 \%$ for the room charge and $4-9 \%$ for the cost from 2011 to 2014. From 2015 onward, the differences significantly increased to 13-14\% for both room charges and cost, which indicates the financial burden due to opioid abuse is increasing with time. 
Table 3. Descriptive Statistics of Treatment (Opioid Abuse Status) and Control Groups' (Non-Opioid Abuse Status) Room Charges and Hospital Costs.

\begin{tabular}{ccccc}
\hline Year & $\begin{array}{c}\text { Treatment Group } \\
(\text { Abuse }=\mathbf{~ 1 )}\end{array}$ & $\begin{array}{c}\text { Room Charges } \\
\text { Control Group } \\
\text { (Abuse }=\mathbf{0})\end{array}$ & $\begin{array}{c}\text { Difference } \\
\text { (Treatment-Control) }\end{array}$ & Percent Change \\
\hline 2011 & $\$ 1211.87$ & $\$ 10,513.54$ & $\$ 1604.33$ & $15.26 \%$ \\
2012 & $\$ 19,251.52$ & $\$ 17,061.79$ & $\$ 2189.73$ & $12.83 \%$ \\
2013 & $\$ 13,967.19$ & $\$ 11,956.54$ & $\$ 2010.65$ & $16.82 \%$ \\
2014 & $\$ 7787.55$ & $\$ 6912.42$ & $\$ 875.13$ & $12.66 \%$ \\
2015 & $\$ 16,150.42$ & $\$ 13,732.43$ & $\$ 2417.98$ & $17.61 \%$ \\
2016 & $\$ 8768.44$ & $\$ 7719.53$ & $\$ 1048.91$ & $13.59 \%$ \\
2017 & $\$ 9628.66$ & $\$ 8343.53$ & $\$ 1285.13$ & $15.40 \%$ \\
& & Hospital Cost & & \\
Year & Treatment Group & Control Group & Difference & Percent Change \\
2011 & $($ Abuse $=1)$ & $($ Abuse $=0)$ & (Treatment-Control) & $15.39 \%$ \\
2012 & $\$ 2484.52$ & $\$ 2153.24$ & $\$ 331.29$ & $12.28 \%$ \\
2013 & $\$ 3568.87$ & $\$ 3178.65$ & $\$ 390.22$ & $15.33 \%$ \\
2014 & $\$ 2462.00$ & $\$ 2134.73$ & $\$ 327.27$ & $12.35 \%$ \\
2015 & $\$ 1318.17$ & $\$ 1173.28$ & $\$ 144.89$ & $20.58 \%$ \\
2016 & $\$ 2690.27$ & $\$ 2231.16$ & $\$ 459.11$ & $13.95 \%$ \\
2017 & $\$ 1505.16$ & $\$ 1320.95$ & $\$ 184.21$ & $16.23 \%$ \\
\hline
\end{tabular}

Table 4. Descriptive Statistics of Treatment (Opioid Abuse Status) and Control Groups (Non-Opioid Abuse Status) Sampling.

\begin{tabular}{|c|c|c|c|}
\hline \multirow[b]{2}{*}{ Year } & \multicolumn{2}{|c|}{ Case-Matching Sample Size } & \multirow[b]{2}{*}{$\begin{array}{c}\text { Total Absolute } \\
\text { Difference }\end{array}$} \\
\hline & $\begin{array}{l}\text { Treatment Group } \\
\quad(\text { Abuse }=1)\end{array}$ & $\begin{array}{l}\text { Control Group } \\
(\text { Abuse }=0)\end{array}$ & \\
\hline 2011 & 5398 & 5398 & 0.086 \\
\hline 2012 & 5400 & 5400 & 0.091 \\
\hline 2013 & 6343 & 6343 & 0.133 \\
\hline 2014 & 7200 & 7200 & 0.089 \\
\hline 2015 & 10,119 & 10,119 & 0.156 \\
\hline 2016 & 8033 & 8033 & 0.131 \\
\hline 2017 & 12,158 & 12,158 & 0.216 \\
\hline
\end{tabular}

Table 5. Data Analysis of Percentage Differences between Treatment (Opioid Abuse) and Control Groups (Non-Opioid Abuse) Associated Room and Hospital Costs.

\begin{tabular}{|c|c|c|c|}
\hline \multicolumn{4}{|c|}{ Percent Difference and $95 \%$ CI in Room Charges } \\
\hline Year & Overall & Surgical Group & Non-Surgical Group \\
\hline Overall & $8.1(7.1,9.1)^{* *}$ & & \\
\hline 2011 & $5.7(-6.1,19.0)$ & $7.4(4.4,10.6) * *$ & $3.9(-17.9,31.6)$ \\
\hline 2012 & $8.1(-5.3,23.3)$ & $4.8(1.6,7.5) * *$ & $11.7(-14.1,45.3)$ \\
\hline 2013 & $4.9(-6.4,17.5)$ & $4.6(1.9,7.4) * *$ & $5.1(-16.1,31.7)$ \\
\hline 2014 & $7.1(-3.9,19.2)$ & $6.8(4.2,9.4) * *$ & $7.4(-13.3,32.9)$ \\
\hline 2015 & $12.9(8.9,17.0) * *$ & $11.0(8.6,13.4) * *$ & $14.8(7.1,23.0) * *$ \\
\hline 2016 & $13.0(10.0,16.2)^{* *}$ & $11.1(8.2,14.1)^{* *}$ & $15.0(9.7,20.1) * *$ \\
\hline 2017 & $8.4(6.1,10.8) * *$ & $6.6(4.3,8.9) * *$ & $10.3(6.2,14.5) * *$ \\
\hline \multicolumn{4}{|c|}{ Percent Difference and 95\% CI in Hospital Cost (Room Charges Multiplied by the Cost-to-Charge Ratio) } \\
\hline Overall & $8.6(7.6,9.6) * *$ & & \\
\hline 2011 & $4.4(-7.6,17.9)$ & $8.8(5.7,12.0) * *$ & $0.1(-21.4,27.5)$ \\
\hline 2012 & $9.4(-4.5,25.3)$ & $3.8(0.8,6.8) * *$ & $15.3(-12.0,51.1)$ \\
\hline 2013 & $3.7(-7.7,16.6)$ & $3.9(1.2,6.8) * *$ & $3.5(-17.9,30.4)$ \\
\hline 2014 & $9.2(-2.3,21.9)$ & $6.2(3.6,8.9) * *$ & $12.2(-9.9,39.8)$ \\
\hline 2015 & $14.6(10.4,18.9)^{* *}$ & $11.2(8.8,13.7)$ ** & $18.0(9.9,26.6) * *$ \\
\hline 2016 & $13.3(10.2,16.6)^{* *}$ & $12.2(9.2,15.3)$ ** & $14.4(8.9,20.2)$ ** \\
\hline 2017 & $9.8(7.4,12.3) * *$ & $8.4(6.0,10.8) * *$ & $11.3(7.1,15.7) * *$ \\
\hline
\end{tabular}

Note: CI: Confidence interval; ${ }^{* *}$ Significant at 0.05 level. 
The surgical and non-surgical subgroups are further examined, and the same pattern over the past seven years was found. The variation in the non-surgical groups is significantly smaller, which makes the differences statistically significant every year. On the other hand, due to the nature of various surgical procedures, the variation in the surgical group is higher, especially from 2011 to 2014. Regardless, the increases in in-room charges and cost in both subgroups have been significantly higher since 2015, indicating that this is a systematic issue that impacts all inpatient populations in Florida.

\section{Discussion}

The findings of this study indicate that the abuse of opioids for Florida patients could lead to a significant financial burden, with the abusing patients incurring $8 \%$ to $10 \%$ more in both charges and costs compared with their non-abusing counterparts. This is consistent with the literature that opioid overdoses cost U.S. hospitals an estimated $\$ 11$ billion annually [34]. The Centers for Disease Control and Prevention estimate that the total "economic burden" of prescription opioid misuse alone in the United States is $\$ 78.5$ billion a year, including the costs of healthcare, lost productivity, addiction treatment, and criminal justice involvement [35]. As the front lines of the opioid epidemic, hospitals are confronted with increasing pressures on capacity and resources related to the diagnosis and treatments of opioids [36]. Opioid-related hospital use, including emergency department visits and inpatient stays, increased significantly over the past decade, which contributes significantly to hospital costs. Opioid abuse and misuse in hospitals may be due to more acute patients in hospitals and increased use and of opioids as a result [15]. The reasons why US hospital opioid use increased include the use of opioids in the management of chronic pain; CMS's reimbursement policy, which is tied to patient care experience measures; and the 2000 Joint Commission's report, as potential drivers for inappropriate opioid administration in hospitals [37]. Studies suggest that clinicians may still rely on outdated Joint Commission standards that defined pain as a "fifth vital sign," leading to overaggressive pain management during hospitalization [38]. In addition, clinicians may inappropriately order opioids due to pressures to obtain better patient care experience scores. CMS decided to temporarily remove two pain-care patient care experience questions from the hospital reimbursement formula starting in 2018 [39]. The CMS plans to add questions on communication about pain care instead. Many hospitals have already responded to the opioid epidemic by changing their prescription of opioid medication practices and the settings in which they are prescribed to reduce these societal and internal costs. There is an increased need for hospitals and clinicians to develop evidence-based prescribing guidelines, encourage safe opioid disposal, and develop patient education materials. In addition, since the prevalence of opioid abuse is not only the responsibility of the hospitals, other community stakeholders should also be involved to reduce the stigma associated with this epidemic.

For example, it is difficult to decrease the cost of healthcare without identifying policies to reduce the incidence of those patients suffering from opioid abuse. As a result, policies that limit the prescribing of opioids or change practices of care by educating providers on the negative impacts of opioid abuse on patient outcomes and costs should be implemented and strengthened. The effect of health insurance on opioid abuse and misuse has been under debate. Some believe that access to health insurance increased access to prescribed opioids. However, policies are increasingly being implemented for insurance companies to monitor opioid usage more closely and to educate providers on proper opioid prescription policies [40]. For example, under the ACA the expansion of health insurance was associated with meaningful reductions in opioid-related hospital use, and the proactive utilization of management care for opioid use disorder among the Medicaid expansion segment [41]. While the effect of health insurance has increased access to prescribed opioids, providers and insurance companies can reduce the need for opioids through best practices to improve health, closer monitoring of opioid usage, proactive prescribing of mental health services, and drug treatment [40]. Furthermore, at-risk patients 
should be educated on opioid addiction and its potential burden in terms of their health and costs. In order to lower healthcare costs, policies should be considered to improve patient, family, and caregiver engagement and encourage them to question the prescribing of opioid medications. Policies that encourage pharmacists to question providers for potentially inappropriate opioid prescription quantities should be encouraged and strengthened [42].

Finally, the findings presented in our study are especially important to providers and hospital administrators who provide uncompensated care to patients who suffer from opioid abuse. Administrators should consider assessing their provider opioid education programs and opioid prescribing trends. In addition, providers should assess their patient opioid education programs on patient outcomes to decrease costs and uncompensated care. Therefore, it is important for hospital administrators to consistently improve and proactively identify solutions to decrease opioid abuse and measurably decrease the cost of care.

\section{Conclusions}

This study provides important insights into Florida's opioid crisis and its financial impact on patients and providers. Our results indicate that there is a significant association between opioid abuse and an increase in both charges and costs in Florida hospitals. Policymakers should understand the impact of this association when developing policies to decrease healthcare costs. Furthermore, insurance companies and pharmacy benefit managers are in a unique position to monitor opioid usage for the insured since they manage prescriptions claims. Effective policies should be implemented by health plans that identify appropriate care and prevention strategies and determine the most effective methods for realizing health outcomes to improve population health and optimize reimbursement, including policies such as value-based purchasing.

Author Contributions: Conceptualization, J.X., H.Y.H., S.P., D.R.H. and M.Z.; methodology, J.X. and H.Y.H.; formal analysis, J.X.; investigation, S.P. and D.R.H.; writing - original draft preparation, J.X., H.Y.H., S.P., D.R.H. and M.Z.; writing-review and editing, J.X., N.M.A.Z., H.Y.H., S.P., D.R.H. and M.Z.; visualization, J.X. and H.Y.H.; supervision, N.M.A.Z., D.R.H. and M.Z.; All authors have read and agreed to the published version of the manuscript.

Funding: This work was supported by the University of Almaarefa. The views expressed in this article are those of the authors and do not necessarily reflect those of the University of Almaarefa. The university was not involved in the design, analysis, and development of the manuscript.

Institutional Review Board Statement: Ethical approval was received for this study (Institutional Review Board \#1422647-3).

Informed Consent Statement: Not applicable.

Data Availability Statement: Restrictions apply to the availability of these data. Data was obtained from the Agency For Health Care Administration in Florida and are available at https:/ /www. floridahealthfinder.gov/Researchers/OrderData/order-data.aspx (accessed on 16 July 2021) with the permission of the Agency For Health Care Administration.

Acknowledgments: The authors would like to thank the University of Almaarefa for its financial support of this research. The authors would also like to thank the University of North Florida, and all the participants in who took part in the study.

Conflicts of Interest: The authors declare no conflict of interests.

\section{References}

1. Substance Abuse and Mental Health Service Association. Find Help: Alcohol, Tobacco, and Other Drugs. Available online: https:/ / www.samhsa.gov/ find-help/atod (accessed on 5 December 2020).

2. Rudd, R.A.; Seth, P.; David, F.; Scholl, L. Increases in Drug and Opioid-Involved Overdose Deaths—United States, 2010-2015. MMWR Morb. Mortal. Wkly. Rep. 2016, 65, 1445-1452. [CrossRef]

3. Gostin, L.O.; Hodge, J.G., Jr.; Noe, S.A. Reframing the Opioid Epidemic as a National Emergency. JAMA 2017, 318, 1539-1540. [CrossRef] [PubMed] 
4. Wilson, N.; Kariisa, M.; Seth, P.; Smith, H., IV; Davis, N.L. Drug and Opioid-Involved Overdose Deaths—United States, 2017-2018. MMWR Morb. Mortal. Wkly. Rep. 2020, 69, 290-297. [CrossRef]

5. Rutkow, L.; Chang, H.Y.; Daubresse, M.; Webster, D.W.; Stuart, E.A.; Alexander, G.C. Effect of Florida's Prescription Drug Monitoring Program and Pill Mill Laws on Opioid Prescribing and Use. JAMA Intern. Med. 2015, 175, 1642-1649. [CrossRef] [PubMed]

6. Delcher, C.; Wagenaar, A.C.; Goldberger, B.A.; Cook, R.L.; Maldonado-Molina, M.M. Abrupt decline in oxycodone-caused mortality after implementation of Florida's Prescription Drug Monitoring Program. Drug Alcohol Depend. 2015, 150, 63-68. [CrossRef]

7. Haley, D.R.; Hamadi, H.; Xu, J.; Zhao, M.; Nguyen, A.V.T.; Martinez, D. Structural and Social Determinants of Opioid Abuse Among Florida-Based Hospitals. Fla. Public Health Rev. 2020, 17, 5.

8. Birnbaum, H.G.; White, A.G.; Reynolds, J.L.; Greenberg, P.E.; Zhang, M.; Vallow, S.; Schein, J.R.; Katz, N.P. Estimated costs of prescription opioid analgesic abuse in the United States in 2001: A societal perspective. Clin. J. Pain 2006, 22, 667-676. [CrossRef]

9. Birnbaum, H.G.; White, A.G.; Schiller, M.; Waldman, T.; Cleveland, J.M.; Roland, C.L. Societal costs of prescription opioid abuse, dependence, and misuse in the United States. Pain Med. 2011, 12, 657-667. [CrossRef]

10. Florence, C.; Luo, F.; Rice, K. The economic burden of opioid use disorder and fatal opioid overdose in the United States, 2017. Drug Alcohol Depend. 2021, 218, 108350. [CrossRef]

11. Luo, F.; Li, M.; Florence, C. State-Level Economic Costs of Opioid Use Disorder and Fatal Opioid Overdose-United States, 2017. MMWR Morb. Mortal. Wkly. Rep. 2021, 70, 541-546. [CrossRef]

12. Kirson, N.Y.; Scarpati, L.M.; Enloe, C.J.; Dincer, A.P.; Birnbaum, H.G.; Mayne, T.J. The Economic Burden of Opioid Abuse: Updated Findings. J. Manag. Care Spec. Pharm. 2017, 23, 427-445. [CrossRef]

13. Rice, J.B.; Kirson, N.Y.; Shei, A.; Cummings, A.K.G.; Bodnar, K.; Birnbaum, H.G.; Ben-Joseph, R. Estimating the costs of opioid abuse and dependence from an employer perspective: A retrospective analysis using administrative claims data. Appl. Health Econ. Health Policy 2014, 12, 435-446. [CrossRef]

14. Peterson, C.; Xu, L.; Mikosz, C.A.; Florence, C.; Mack, K.A. US hospital discharges documenting patient opioid use disorder without opioid overdose or treatment services, 2011-2015. J. Subst. Abus. Treat. 2018, 92, 35-39. [CrossRef]

15. Wu, B.U.; Butler, R.K.; Chen, W. Factors associated with opioid use in patients hospitalized for acute pancreatitis. JAMA Netw. open 2019, 2, e191827. [CrossRef]

16. Rice, J.B.; Kirson, N.Y.; Shei, A.; Enloe, C.J.; Cummings, A.K.G.; Birnbaum, H.G.; Holly, P.; Ben-Joseph, R. The Economic Burden of Diagnosed Opioid Abuse Among Commercially Insured Individuals. Postgrad. Med. 2014, 126, 53-58. [CrossRef]

17. White, A.G.; Birnbaum, H.G.; Mareva, M.N.; Daher, M.; Vallow, S.; Schein, J.; Katz, N. Direct costs of opioid abuse in an insured population in the United States. J. Manag. Care Pharm. 2005, 11, 469-479. [CrossRef] [PubMed]

18. Gupta, A.; Nizamuddin, J.; Elmofty, D.; Nizamuddin, S.L.; Tung, A.; Minhaj, M.; Mueller, A.; Apfelbaum, J.; Shahul, S. Opioid Abuse or Dependence Increases 30-day Readmission Rates after Major Operating Room Procedures: A National Readmissions Database Study. Anesthesiology 2018, 128, 880-890. [CrossRef]

19. White, A.G.; Birnbaum, H.G.; Schiller, M.; Waldman, T.; Cleveland, J.M.; Roland, C.L. Economic Impact of Opioid Abuse, Dependence, and Misuse. Am. J. Pharm. Benefits 2011, 3, e59-e70.

20. Ghate, S.R.; Haroutiunian, S.; Winslow, R.; McAdam-Marx, C. Cost and comorbidities associated with opioid abuse in managed care and Medicaid patients in the United Stated: A comparison of two recently published studies. J. Pain Palliat Care Pharm. 2010, 24, 251-258. [CrossRef] [PubMed]

21. McAdam-Marx, C.; Roland, C.L.; Cleveland, J.; Oderda, G.M. Costs of opioid abuse and misuse determined from a Medicaid database. J. Pain Palliat Care Pharm. 2010, 24, 5-18. [CrossRef]

22. Oderda, G.M.; Lake, J.; Rüdell, K.; Roland, C.L.; Masters, E.T. Economic Burden of Prescription Opioid Misuse and Abuse: A Systematic Review. J. Pain Palliat. Care Pharmacother. 2015, 29, 388-400. [CrossRef] [PubMed]

23. Pasquale, M.K.; Joshi, A.V.; Dufour, R.; Schaaf, D.; Mardekian, J.; Andrews, G.A.; Patel, N.C. Cost drivers of prescription opioid abuse in commercial and Medicare populations. Pain Pract. 2014, 14, E116-E125. [CrossRef]

24. Masson, C.L.; Sorensen, J.L.; Batki, S.L.; Okin, R.; Delucchi, K.L.; Perlman, D.C. Medical service use and financial charges among opioid users at a public hospital. Drug Alcohol Depend. 2002, 66, 45-50. [CrossRef]

25. Chandwani, H.S.; Strassels, S.A.; Rascati, K.L.; Lawson, K.A.; Wilson, J.P. Estimates of charges associated with emergency department and hospital inpatient care for opioid abuse-related events. J. Pain Palliat Care Pharm. 2013, 27, 206-213. [CrossRef] [PubMed]

26. Leslie, D.L.; Ba, D.M.; Agbese, E.; Xing, X.; Liu, G. The economic burden of the opioid epidemic on states: The case of Medicaid. Am. J. Manag. Care 2019, 25, S243-S249. [PubMed]

27. Heslin, K.C.; Owens, P.L.; Karaca, Z.; Barrett, M.L.; Moore, B.J.; Elixhauser, A. Trends in Opioid-related Inpatient Stays Shifted After the US Transitioned to ICD-10-CM Diagnosis Coding in 2015. Med. Care 2017, 55, 918-923. [CrossRef]

28. Moore, B.J.; Barrett, M.L. Case Study: Exploring How Opioid-Related Diagnosis Codes Translate From ICD-9-CM to ICD-10-CM. Available online: https:/ / www.hcup-us.ahrq.gov / reports/methods/methods.jsp (accessed on 1 November 2018).

29. Kenward, M.G.; Roger, J.H. Small sample inference for fixed effects from restricted maximum likelihood. Biometrics 1997, 53, 983-997. [CrossRef]

30. Bai, H.; Clark, M.H. Propensity Score Methods and Applications; Sage Publications: Thousand Oaks, CA, USA, 2018. 
31. Stroup, W.W. Generalized Linear Mixed Models: Modern Concepts, Methods and Applications; CRC Press: Boca Raton, FL, USA, 2012.

32. Institute, S. SAS 9.4 Output Delivery System: User's Guide; SAS Institute: Cary, NC, USA, 2014.

33. Keselman, H.J.; Algina, J.; Kowalchuk, R.K.; Wolfinger, R.D. A comparison of two approaches for selecting covariance structures in the analysis of repeated measurements. Commun. Stat.-Simul. Comput. 1998, 27, 591-604. [CrossRef]

34. Premier Inc. Opioid Overdoses Costing, U.S. Hospitals an Estimated \$11 Billion Annually. Available online: https://www. premierinc.com/newsroom/press-releases/opioid-overdoses-costing-u-s-hospitals-an-estimated-11-billion-annually (accessed on 5 December 2019).

35. Collins, F.S.; Koroshetz, W.J.; Volkow, N.D. Helping to end addiction over the long-term: The research plan for the NIH HEAL initiative. JAMA 2018, 320, 129-130. [CrossRef]

36. Dasgupta, N.; Beletsky, L.; Ciccarone, D. Opioid crisis: No easy fix to its social and economic determinants. Am. J. Public Health 2018, 108, 182-186. [CrossRef]

37. World Health Organization. Opioid Overdose. Available online: https://www.who.int/news-room/fact-sheets/detail/opioidoverdose (accessed on 18 August 2021).

38. Baker, D.W. History of The Joint Commission's pain standards: Lessons for today's prescription opioid epidemic. JAMA 2017, 317, 1117-1118. [CrossRef]

39. Federal Register. Medicare Program: Hospital Outpatient Prospective Payment and Ambulatory Surgical Center Payment Systems and Quality Reporting Programs; Organ Procurement Organization Reporting and Communication; Transplant Outcome Measures and Documentation Requirements; Electronic Health Record (EHR) Incentive Programs; Payment to Nonexcepted Off-Campus Provider-Based Department of a Hospital; Hospital Value-Based Purchasing (VBP) Program; Establishment of Payment Rates Under the Medicare Physician Fee Schedule for Nonexcepted Items and Services Furnished by an Off-Campus Provider-Based Department of a Hospital. 2016. Available online: https:/ /www.federalregister.gov/documents/2017/04/06/2 017-06903/medicare-program-hospital-outpatient-prospective-payment-and-ambulatory-surgical-center-payment (accessed on 7 June 2020).

40. Wettstein, G. Health insurance and opioid deaths: Evidence from the Affordable Care Act young adult provision. Health Econ. 2019, 28, 666-677. [CrossRef] [PubMed]

41. Wen, H.; Soni, A.; Hollingsworth, A.; Freedman, S.; Benitez, J.; Simon, K.; Saloner, B. Association between Medicaid expansion and rates of opioid-related hospital use. JAMA Intern. Med. 2020, 180, 753-759. [CrossRef] [PubMed]

42. Custer, W.S. The Opioid Epidemic and Health Plans. J. Financ. Serv. Prof. 2017, 71, 40-42. 